\title{
Natural Dynamics of Multi-Species Flowering Annuals in Tropical Landscape
}

\author{
Hanim Ahmad*, Hamdan Mohd Noor, Zulhazmi Sayuti \\ Horticulture Research Centre, Malaysian Agriculture Research and Development Institute, Serdang, Malaysia \\ Email address: \\ hanim@mardi.gov.my (H.Ahmad) \\ ${ }^{*}$ Corresponding author
}

\section{To cite this article:}

Hanim Ahmad, Hamdan Mohd Noor, Zulhazmi Sayuti. Natural Dynamics of Multi-Species Flowering Annuals in Tropical Landscape. Landscape Architecture and Regional Planning. Vol. 3, No. 2, 2018, pp. 28-33. doi: 10.11648/j.larp.20180302.12

Received: January 18, 2018; Accepted: May 2, 2018; Published: May 28, 2018

\begin{abstract}
This study investigate the growth performance and the dynamic community of multi-species annual flowers in tropical landscape. The multi-species plant community produce an attractive colour of flowers according to their flowering peak of each species that have been tested. At the first growth cycle, the earliest species to bloom were Gomphrena globosa and Zinnia elegans which took 8 weeks after seed were sown. Meanwhile, Cosmos spp and Tithonia rotundifolia were the late species to bloom which took 14 weeks after seeds were sown. At the second growth cycle, the multi-species annual plants bloom much earlier which is only 3 weeks after pruning. The mean plant height and dry weight of several species on both growth cycles show a significant difference $(\mathrm{P}<0.05)$. Cosmos sulphureus and Cosmos caudatus recorded maximum heights on both growth cycles with $C$. sulphureus recording a maximum dry weight of about $172.5 \mathrm{gm} / \mathrm{plant}$ in the first growth cycle. Overall, the established multi-species plant community developed, had a lifespan of 5- 6 months in each growth cycle. The second growth cycle plant community was formed through self-sowing and vegetative part after pruning.
\end{abstract}

Keywords: Natural Dynamic, Landscape, Multi-Species, Flowering Annuals

\section{Introduction}

Annual flowers are popular ornamental plants that are used in landscaping. They are grown to add color in a garden [1, 2]. Conventionally, annual flowering plants are propagated and grown in a nursery until they produce buds or flowers before being transferred to the landscape areas. Generally, plants that are transferred to the landscape especially in tropical urban areas have a short life span of approximately $1-1 \frac{1}{2}$ months after being used as landscape component. Thus, the plant should be replaced with a new batch of different or same ornamental species. In landscape management perspectives, this approach is considered unsustainable. It involves high cost of planting materials and maintenance. Therefore, to resolve this problem, the technique of directly sowing multi-species flowering annuals in the tropical landscape area has a potential to be practiced [3].

Previous studies have shown that growing ornamental plants by mixing results in an attractive array of flower colours can conserve biodiversity and reduces maintenance cost [4]. Moreover, the mixing of ornamentals produces a new community of plants that is dynamic; providing an impact of a natural landscape that attracts visitors $[5,6,7]$. The dynamic change in landscape plants community based on the flowering phenology and growth rate are dependent upon time and the space allocated for landscaping.

Knowledge on species suitability and patterns of long run dynamic change in the plants community are essential to be identified from a landscape planning perspective [4, 8]. This is to ensure that the right species of ornamental plants would be chosen in order to produce an interesting impact of flowers. Since these areas are yet to be explored, the objective of this study is to identify the natural dynamics of mixing several multi-species flowering annuals in tropical landscape.

\section{Materials and Methods}

\subsection{Species Selection and Maintenance}

This study was conducted at the Malaysian Agricultural Research and Development Institute (MARDI), Ornamental Complex, Serdang, Malaysia. The plot was flat and exposed 
to full sunlight. During site preparation, weeds were sprayed with glyphosate herbicide and removed manually to achieve plant free conditions. Soil surfaces were then mowed to a depth of $300 \mathrm{~mm}$ and leveled. River sand as thick as $20 \mathrm{~cm}$ was used as a growth medium while retaining the original soil surface beneath [9].

A total of ten species of flowering annuals were selected for this study (Table 1). The annual flowers species were selected based on their availability, aesthetic values, flowering phenology, adaptation to urban tropical climate and competitiveness among species in Malaysia urban landscape. All sources of the seeds were collected locally from MARDI seed production plots. Seeds which were not available naturally were obtained from commercial nursery. Such seeds included Cosmos sulphureus and Gomphrena globosa.

Table 1. Flowering annual plants that were studied.

\begin{tabular}{llll}
\hline Species & Family & $\begin{array}{l}\text { Plant type/ } \\
\text { habitat* }\end{array}$ & $\begin{array}{l}\text { Flower } \\
\text { colour }\end{array}$ \\
\hline Catharanthus roseus & Apocynaceae & Annual / dry-wet & Pink \\
Catharanthus roseus & Apocynaceae & Annual / dry-wet & White \\
Cosmos caudatus & Asteraceae & Annual / dry-wet & Pink \\
Cosmos sulphureus & Asteraceae & Annual / dry-wet & Yellow \\
Gomphrena globosa & Amaranthaceae & Annual / dry-wet & Orange \\
Impatiens balsamina & Balsaminaceae & Annual / dry-wet & Red \\
Impatiens balsamina & Balsaminaceae & Annual / dry-wet & Purple \\
Tagetes erecta & Asteraceae & Annual / dry-wet & Yellow \\
Tithonia rotundifolia & Asteraceae & Annual / wet & Orange \\
Zinnia elegans & Asteraceae & Annual / dry-wet & Yellow \\
\hline
\end{tabular}

*Normal environment

The selected flowering annual plants were directly sown in an experimental plot measuring $200 \mathrm{~cm}$ in length $\mathrm{x} 200 \mathrm{~cm}$ in width $\times 20 \mathrm{~cm}$ in height. Three seeds of flowering annual plants were sown at each planting hole with a distance of $20 \mathrm{~cm} \times 20$ $\mathrm{cm}$ in between species with 10 rows. The experimental design is a completely randomized design. Once the seedling is as tall as 5 $\mathrm{cm}$, the thinning process was conducted by retaining one plant per planting hole. A week after sowing, the seedlings were fertilized with the NPK compound 15:15:15 at approximately $15 \mathrm{~g} / \mathrm{m}^{2}$. The organic fertilizer, Jutani at approximately $150 \mathrm{~g} / \mathrm{m}^{2}$ was re-applied once a month afterwards. The plants were watered in the mornings and evenings as necessary to prevent severe stress, subsequently reduced once the plant reaches maturity. Permanent quadrates $(180 \times 180 \mathrm{~cm})$ were established for data collection. Within each quadrate, seedling emergence, flowering phenology, plant height and dry weight data were collected.

\subsection{Statistical Analysis}

Numbers of seedling emergence from the experiment were converted to percentages (seeds germinated/emerged as a percentage of those sown). As Kolmogorov-Smirnov tests indicated that counted data was non-normal and could not be adequately improved by transformation, analysis was undertaken using non-parametric tests [10]. Statistical analysis was undertaken using SPSS version 15 for windows. The Mann-Whitney $U$-test was used in lieu of $t$-test for paired comparisons. This test was used to compare the significant differences of plant performance between first and second growth cycles.

\section{Results and Discussion}

\subsection{Seed Germination}

The species varied in their emergence patterns. In general, field emergence was considerably low for most annual species tested in the first growth cycle (Figure 1), with the best germination achieved was of approximately only $20 \%$ (Catharanthus roseus, Cosmos spp. and Impatiens balsamina). This situation could have occurred possibly due to poorer seed quality and less favourable environmental conditions. Meanwhile, in the second growth cycle, Cosmos spp. had the highest percentage of germination $(78 \%)$ as compared to other species. Emergence is strongly affected by seed quality $[11,12]$ and environmental factors such as rainfall/irrigation $[12,13]$, soil type [14], predation [15] and temperature $[14,16,17]$.

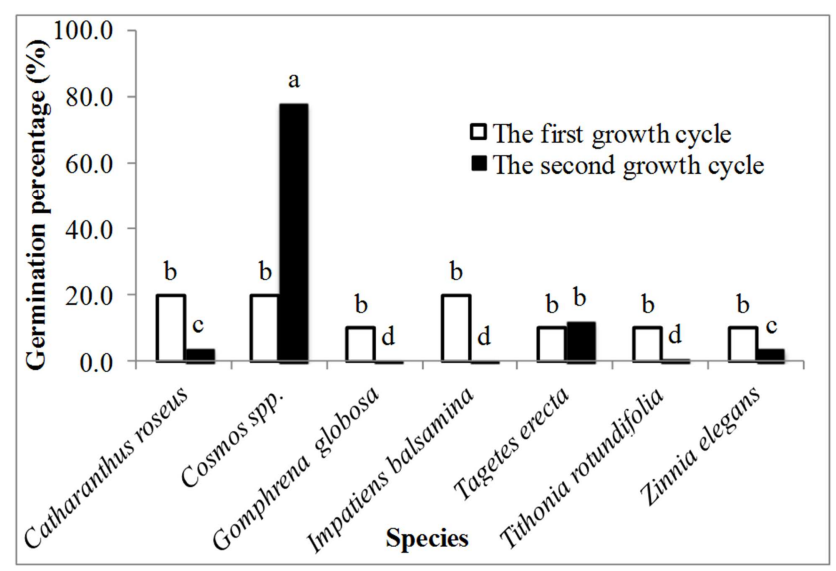

Figure 1. Seed germination of flowering annuals species. Bar labeled with different letters are significantly different between species in each growth cycle at $P<0.05$ (Kruskal-Wallis test).

In this study, attempts were made to minimise predation by regular baiting with metaldehyde. This suggests that lower emergence was substantially due to hot and dry weather in the tropic, leading to death of seedlings at germination stage. The results of this study indicate that self-sowing occurs to create plant community for the second growth cycles. Overall, flowering annuals species in the community between two plant growth cycles shows different percentage of seed germination after 2 weeks of pruning.

\subsection{Multi-species Flowering Phenology}

Results indicate that plants in the community bloom at different periods depending on the species and its growth cycle (Figure 2). The peak flowering of multi-species ranged from about 10 weeks after sowing to flower senescence (12 weeks). In the first growth cycle, Gomphrena globosa and Zinnia elegans started to flower earlier; Cosmos caudatus, Cosmos sulphureus and Tithonia rotundifolia were the late flowering 
species. Multi-species plant community in the second growth cycle shows an earlier flowering phenology, approximately 3 weeks after pruning. Catharanthus roseus 'pink', Gomphrena globosa and Zinnia elegans started to flower earlier; Cosmos caudatus took longer time to bloom. This makes the landscape plot more attractive with various colours of flowers in the tropical climates. This flowering pattern is similar to that recorded in previous studies on mixing plant community [9, 18]. Mixing of multi-species produced different plant blooming with interesting flowers in the experimental plot.

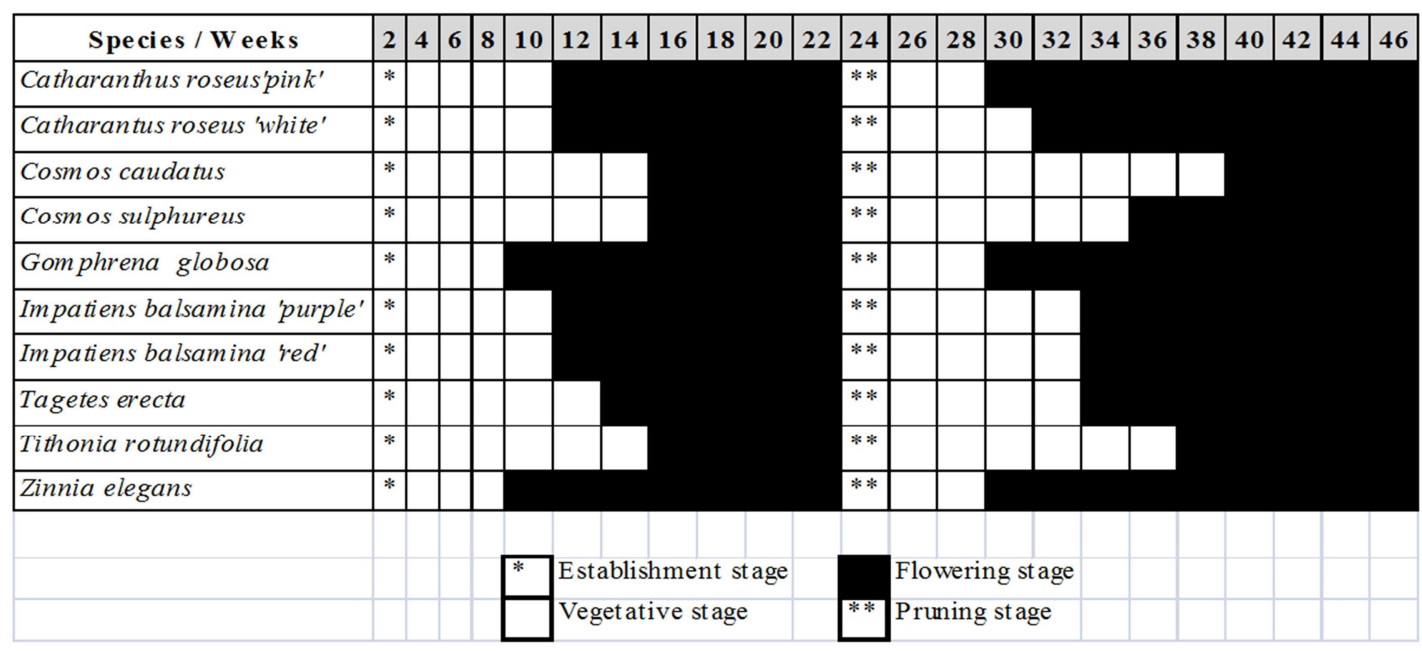

Figure 2. Flowering phenology of multi-species plants in the two growth cycle.

\subsection{Pattern of The Multi-species Plant Community}

Multi-species flowering annuals produce different plant structures and flowering pattern according to the duration of growth and planting space. Each month, various types of landscape scenery can been seen depending on the flowering phenology of each species in the landscape area (Figure 3).
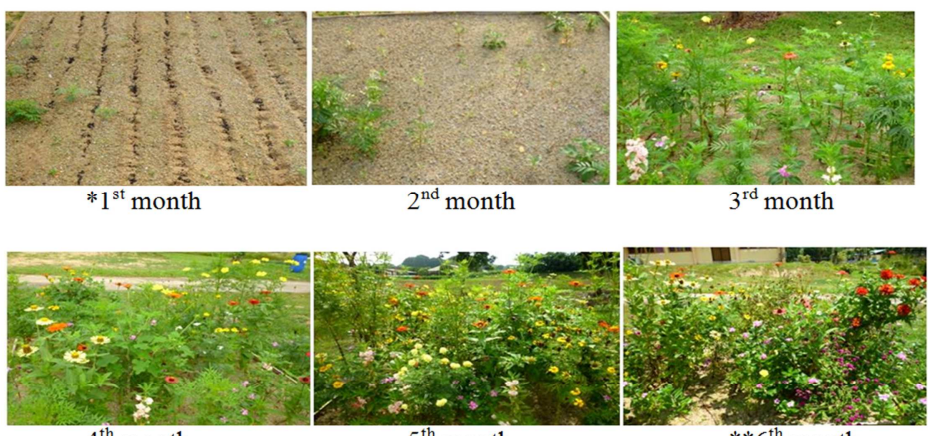

$4^{\text {th }}$ month

$5^{\text {th }}$ month

$* * 6^{\text {th }}$ month
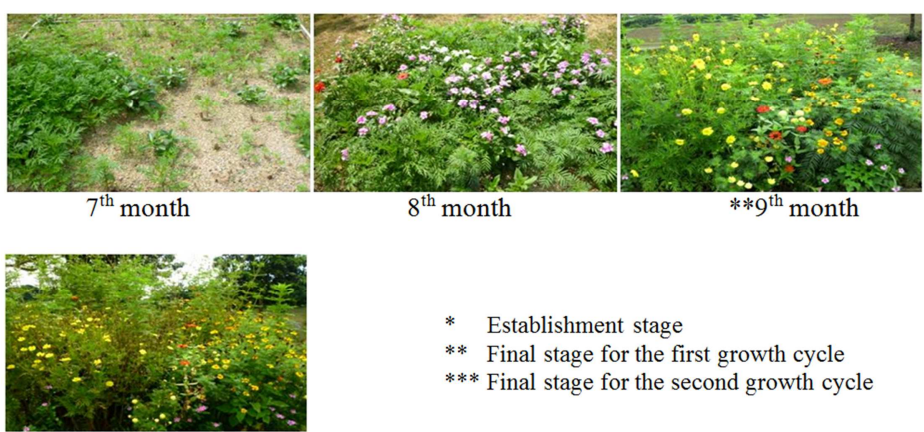

** Final stage for the first growth cycle

*** Final stage for the second growth cycle

$* * * 10^{\text {th }}$ month

Figure 3. The dynamic change of flowering annual plants in the same landscape area.

Diversity of multi-species gives a long period of more pattern in display within a small plot area $[4,9]$. This is very different from the sort of pattern in display generated through standard horticultural block planting, where continuity of scenery may occur over larger distances. The growth pattern of multi-species through the growing period can be a crucial factor in creating compatable mixtures of species that have a long period of display [4]. 


\subsection{Species Performance}

The multi-species community that was planted for 10 months and had encounter two growth cycles was studied. The data was analyzed in terms of the plants performance; plant height, dry weight and percentage of species survival, in two growth cycle.

\subsubsection{Height and Dry Weight of Plants}

Figure 4a shows the average of plant height within two growing cycles grow in the community. Results indicate that several species had significant differences between the first and second growth cycle $(\mathrm{P}<0.05)$. In the first growth cycle the species that obtained maximum height was Cosmos sulphureus $(182 \mathrm{~cm})$, where else on the second growth cycle was Cosmos caudatus $(164 \mathrm{~cm})$. Impatiens balsamina 'purple' and Impatiens balsamina 'red' also had significant increase in plant height in the first growth cycle. Meanwhile, Zinnia elegans and Catharanthus roseus 'white' also showed an increase in the second growth cycle. Nevertheless, the results suggest that Cosmos is the dominant species grown in the community as compared to the other species tested. Some of the species in this study increased their plant height due to fast growth and competition for light within the species $[4,19,20]$.

Figure $4 \mathrm{~b}$ shows the average of dry weight of plant within two growing cycles grow in community. Dry weight of individual species (gm/plant) was significantly different in Catharanthus roseus 'pink', Catharanthus roseus 'white', Cosmos sulphureus, Impatiens balsamina 'purple', Impatiens balsamina 'red', Tagetes erecta and Tithonia rotundifolia, Dry weight was not significantly different in Cosmos caudatus, Gomphrena globosa and Zinnia elegans. Cosmos sulphureus had the maximum dry weight (172.5 gm/plant) in the first growth cycle. This suggests that the greatest dry weight was obtained in Cosmos species may due to the abundant numbers (high seedling density) of plants re-generate through selfseeding at the end of cycle. The same trend was also observed for ornamental herbaceous species when planted in a landscape area using the same approach $[18,21]$. It was also reported that high seedling density increased competitive elimination of slow growing species [4].

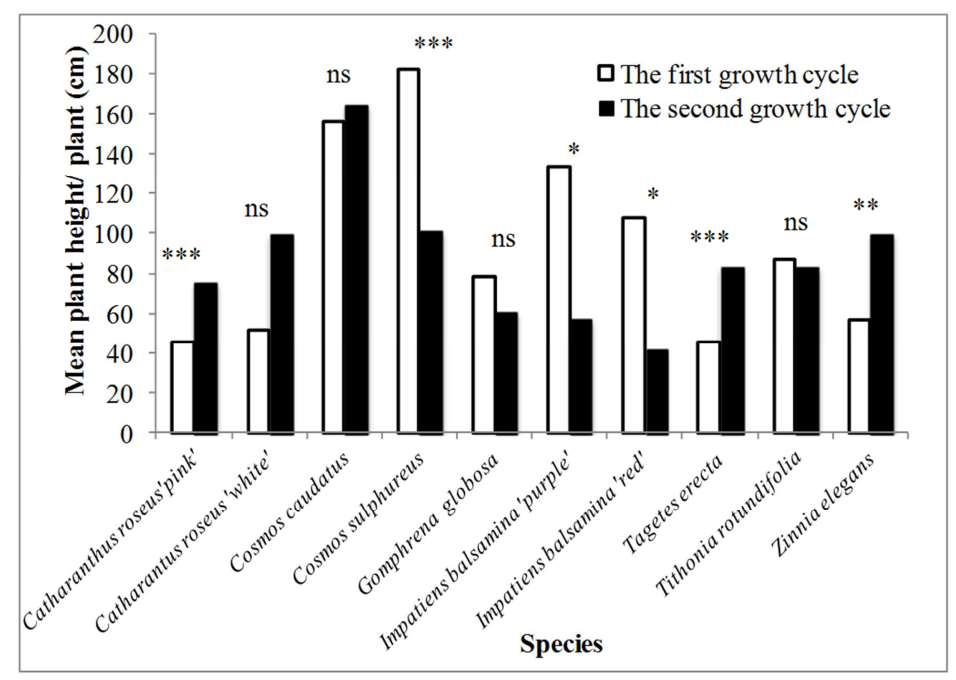

(a)

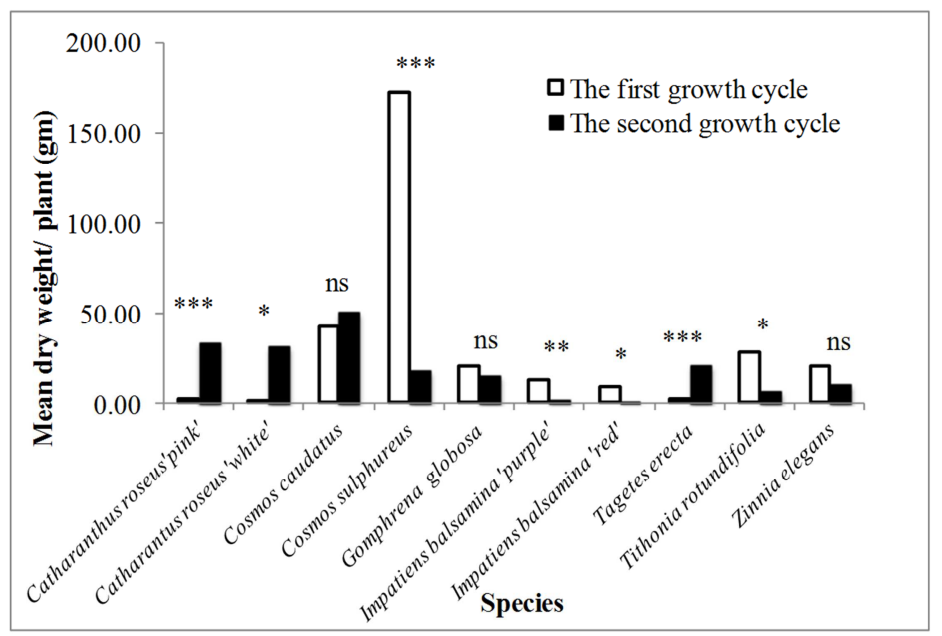

(b)

Figure 4. Mean height (a) and dry weight (b) of each species per plant. Identical letters on the bar chart indicate no significant difference between the two growth cycle (Mann-Whitney U-test; ${ }^{*} 0.05 ; * * 0.01 ; * * * 0.001 ; n s-n o t$ significant). 
On the first growth cycle the species that obtained maximum height is Cosmos sulphureus $(182 \mathrm{~cm})$, where else on the second growth cycle was Cosmos caudatus $(164 \mathrm{~cm})$. Cosmos sulphureus had the maximum dry weight (172.5 gm/ plant) in the first growth cycle.

\subsubsection{Species Survival}

Actual numbers of plant established from the experiment during the first growth cycle were used as the reference point to compare subsequent species survival in the second growth cycle. Figure 5 shows the percentage of species survival of flowering annuals in the second growing cycle. It was found that the species survival varies between species, with Cosmos sulphureus obtaining the highest percentage of survival (28.3\%), followed by Tagetes erecta $(22.0 \%)$. Meanwhile Catharanthus roseus 'white' showed the lowest percentage of the species survival $(0.5 \%)$.

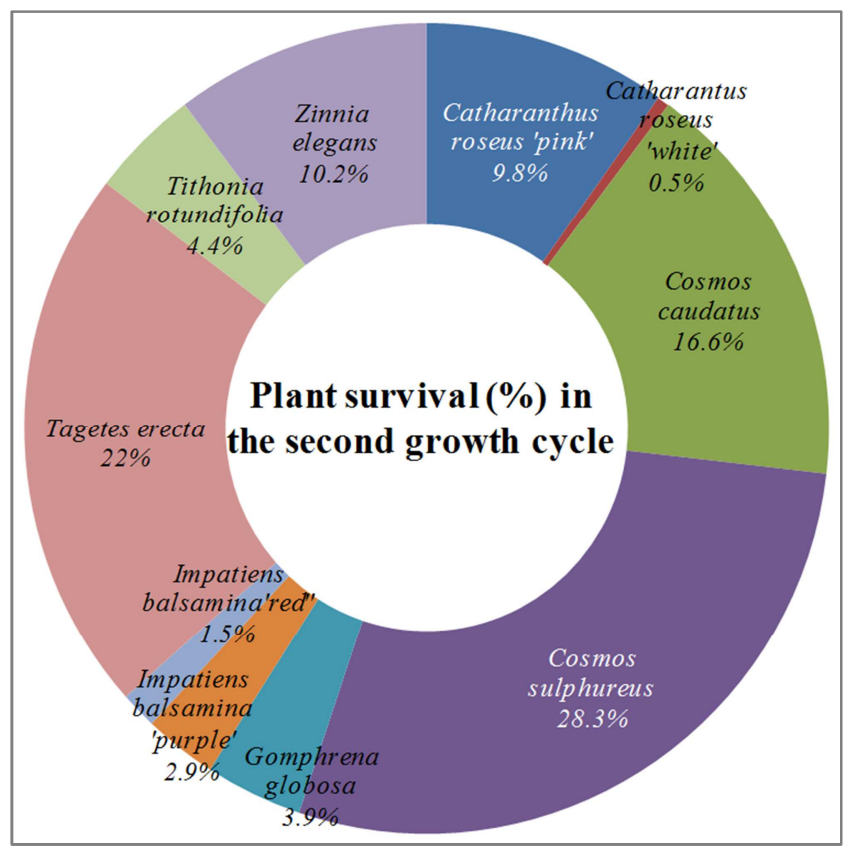

Figure 5. Percentage of species survival for the second growth cycle.

Overall, survivorship of flowering annual species was high, despite compete with weeds. Weeds reduce growth of desired plants through competition may involve either or both of above ground (shoot) and below ground (root) competition [19, 20, 22]. Possibly, competitive elimination of a species by its neighbour occurs due to differences in seedling size and growth rate between different species in communities. Fast growing species produces dense foliage therefore it will be affected to the other species which are slow growing and eliminating small seedlings.

\section{Conclusions}

This study provides information on the growth of the mixed species community of flowering annual plants in tropical landscape area. For the first growing cycles, all of the species can grow well and produce an attractive flower impact with a long flowering period of 12 weeks, with peaks flowering 14 weeks after seed sowing. Similarly, long flowering periods of more than 12 weeks are exhibited by multi-species plant communities which created through selfsowing in the second growth cycle. Several species such as Cosmos spp., Tagetes erecta and Zinnia elegans were found more dominant in the community of the second growth cycle. These species are dominated due to the re-germination of seeds after the first growth cycle. Meanwhile Catharanthus spp dominate through vegetative parts; growth of new shoots from pruned stumps. Based on this study, it is suggested that growing a multi-species flowering annuals in urban tropical landscapes has the potential to be practiced. Through this approach, an attractive plant community that is natural looking and colourful in a landscape area can be created. This community is more dynamic, has long flowering periods and can continue their life cycle through self sowing and growing of vegetative part.

\section{References}

[1] Grey-Wilson, C. 2000. The Royal Horticultural Society Practical Guides; Annuals and biennials. London: Dorling Kindersley.

[2] Powling, S. 1992. All colour flower garden. London: Hamlyn, Octopus Illustrated Publishing.

[3] Hanim, A., Ab Kahar, S. and Mohd Mokhlas, M. S. 2010. Penanaman Zinnia di kawasan landskap secara penyemaian terus. Buletin Teknologi Tanaman MARDI. 7:1-7.

[4] Dunnett, N. and Hitchmough, J. D. 2004. The dynamic landscape; Design, ecology and management of naturalistic urban planting. London: Spon Press.

[5] Southon, G. E., Jorgensen, A., Dunnett, N., Hoyle, H., Evans, K. L. 2017. Biodiverse perennial meadows have aesthetic value and increase residents' perceptions of site quality in urban green-space. Landscape and Urban Planning. 158, $105-118$.

[6] Todorova, A., Asakawa, S., Aikoh, T. 2004. Preferences for and attitudes towards street flowers and trees in Sapporo, Japan. Landscape and Urban Planning. 69 (4), 403-416.

[7] Hoyle, H., Hitchmough, J. and Jorgensen, A. 2017. All about the 'wow factor'? The relationships between aesthetics, restorative effect and perceived biodiversity in designed urban planting. Landscape and Urban Planning, 164, 109-123.

[8] Sjöman, H., Bellan, P., Hitchmough, J. and Oprea, A. 2015. Herbaceous plants for climate adaptation and intensely developed urban sites in northern Europe: a case study from the eastern Romanian Steppe. Ekologia, 34(1), 39-53.

[9] Hanim, A., Nazera, A. and Ab Kahar, S. 2011. Establishing annual multi-species community in urban landscapes: Effect of different inorganic mulch types in relation to seed germination, weed biomass and plant growth. National Horticulture Conference, 18-20 October 2011, Melaka. 
[10] Dytham, C. 2003. Choosing and using statistics. A biologists guide. York: Blackwell Publishing Company.

[11] Lehtila, K., and Ehrlen, J. 2005. Seed size as an indicator of seed quality: a case study of Primula veris. Acta Oecologica 28(33), 207-212.

[12] Penfield, S. and MacGregor, D. R. 2017. Effects of environmental variation during seed production on seed dormancy and germination. Journal of Experimental Botany, 68(4), pp.819-825.

[13] Pelaez, D. V., Boo, R. M., and Elia, O. R. 1996. The germination and seedling survival of Condalia microphylla Cav. in Argentina. Journal of Arid Environments 32, 173-179.

[14] Forcella, F., Arnold, R. L. B., Sanchez, R., and Ghersa, C. M. (2000). Modelling seedling emergence. Field Crops Research 67, 123-139.

[15] Clarke, P. J., and Davison, E. A. 2004. Emergence and survival of herbaceous seedlings in temperate grassy woodlands: Recruitment limitations and regeneration niche. Austral Ecology 29, 320-331.

[16] Shimono, A., and Washitani, I. 2004. Seedling emergence patterns and dormancy/germination physiology of Primula modesta in a subalpine region. Ecological Research (2004) 19, 541-551.
[17] Zettlemoyer, M. A., Prendeville, H. R. and Galloway, L. F. 2017. The effect of a latitudinal temperature gradient on germination patterns. International Journal of Plant Sciences, 178(9), 673-679.

[18] Hitchmough, J. D., Wagner, M. and Ahmad, H. 2017. Extended flowering and high weed resistance within two layer designed perennial "prairie-meadow" vegetation. Urban Forestry and Urban Greening. 27, 117-126.

[19] Brenda, B. C. and Robert, B. J. 1997. Plant competition underground. Annual review of ecology and systematics, 28, 545-570.

[20] Bhadouria, R., Srivastava, P., Singh, S., Singh, R., Raghubanshi, A. S. and Singh, J. S. 2018. Effects of light, nutrient and grass competition on growth of seedlings of four tropical tree species. Indian Forester, 144(1), 54-65.

[21] Hitchmough, J. D. and Woudstra, J. 1999. The ecology of exotic herbaceous perennials grown in managed, native grassy vegetation in urban landscapes. Landscape and Urban Planning, 45, 107-121.

[22] Gibson, D. J., Young, B. G. and Wood, A. J. 2017. Can weeds enhance profitability? Integrating ecological concepts to address crop-weed competition and yield quality. Journal of Ecology, 105(4), 900-904. 